\title{
ENERGY AND ENVIRONMENTAL EVALUATION OF MICRO-COGENERATION SYSTEM FOR CONVENIENCE STORES IN THAILAND
}

\author{
${ }^{1}$ Suapphong Kritsanawonghong, ${ }^{1}$ Weijun Gao, \\ ${ }^{2}$ Pawinee Iamtrakul and ${ }^{1}$ Soichiro Kuroki \\ ${ }^{1}$ Department of Architecture, Faculty of Environmental Engineering, \\ The University of Kitakyushu, Kitakyushu, Japan \\ ${ }^{2}$ Department of Urban Environmental Planning and Development, \\ Faculty of Architecture and Planning, Thammasat University, Pathum Thani, Thailand
}

Received 2014-04-11; Revised 2014-04-18; Accepted 2014-05-15

\begin{abstract}
The growing worldwide demand for effective energy utilization has led to numerous techniques for rational use of energy including conservation techniques and renewable energy utilization. Recently, the number of small scale buildings such as minimarts and convenience stores in Thailand has increased rapidly. However, the interest of effective energy utilization has not been focused on the implementation of the new technologies due to high investment and lack of skilled workers for the maintenance. In this study, the benefit of the implementation of micro-cogeneration systems driven by natural gas engines to meet the energy demand of Thailand's convenience stores has been analyzed using two assessment indices, Primary Energy Saving ratio (PES) and $\mathrm{CO}_{2}$ Emission Reduction ratio (CER) to evaluate the energy and environmental impact. The analysis results have shown that from the consideration of the energy production from micro-cogeneration systems, the selection of the reasonable capacity of the system depends on the characteristic of the load profile and the objective of the utilization of micro-cogeneration system. Furthermore, the electrical and thermal efficiencies of the micro-cogeneration system are important factors that cannot be ignored in an effect to enhance the performance of micro-cogeneration systems for both energy saving and environmental benefits. The results showed that PES and CER values can be increased up to 45 and $88 \%$, respectively, due to the utilization of higher efficiencies of micro-cogeneration system.
\end{abstract}

Keywords: Convenience Store, Micro-Cogeneration, $\mathrm{CO}_{2}$ Emission Reduction, Primary Energy Saving, Thailand

\section{INTRODUCTION}

Implementation of alternative energy to support increased demand is one effective way to meet energy consumption needs and to reduce environmental pollution caused from the emissions being released. The cogeneration, which produces electricity with heat utilization, is also called CHP system, or combined heat and power, which makes electricity with heat utilization. This is a potentially a significant technology to provide effective energy utilization and environmental benefits for both the commercial and industrial sectors in Thailand. A number of studies have investigated CHP systems integrated in various building types by several assessment indices, i.e., energy saving, environmental benefits and economic index.

Utilization of the CHP system in several building types which require power, cooling and heating (i.e., shopping malls, supermarkets, department stores, hospitals and hotels) for energy saving and the

Corresponding Author: Suapphong Kritsanawonghong, Department of Architecture, Faculty of Environmental Engineering, The University of Kitakyushu, Kitakyushu, Japan 
environmental load reduction purposes have been the focus of many research projects. Sommart and Chullapong (2005) studied the benefits of the implementation of the CHP system integrated with an absorption chiller in the Supercenter Building in Thailand by varying 2 types of CHP systems and 3 types of absorption chillers by considering the payback period as the economic assessment index. The results showed that the average payback period is about 8.935.5 years from the integrated system between gas turbine cogeneration with all absorption chillers. Maidment et al. (1999) developed a mathematical model to show the benefit that CHP system implementation in supermarkets with the acceptable primary energy saving and acceptable payback period. Sugiartha et al. (2009) presented various evaluation methods for the utilization of micro-gas turbine based trigeneration systems for supermarkets in the United Kingdom by comparing the energy efficiency, economic and environmental performance between the trigeneration system and conventional systems. In contrast to the conventional system, the system is sensitive to the prices of grid electricity and natural gas, which also affects the payback period of this system. Iman et al. (2008) studied the economical viewpoint for consumers and producers from the utilization of ICECHP by using electricity direct pricing and actual annual benefit methods. It was found that by using electricity direct pricing method, ICECHP with gasohol were uneconomical for consumers but E5 and E10 is economical for producers. From acual annual benefits method, ICECHP with E5 was economical for consumer and up to E20 for producers.

The environmental benefits from the utilization of CHP system for commercial buildings has been examined by Pedro and Amanda (2012), who investigated seven different types of buildings in the United States, looking for potential ways to reduce $\mathrm{CO}_{2}$, $\mathrm{NO}_{\mathrm{x}}$ and $\mathrm{CH}_{4}$ emissions as well as ways to save primary energy using the CHP system. They found that employing a CHP system would reduce carbon equivalent emissions in all the buildings by more than $21 \%$ and that primary energy saving leading to a decrease in operation costs can be achieved in some buildings. Yingjun et al. (2009) constructed a model of distributed generation technologies for four different kinds of commercial buildings in Japan by considering the energy consumption characteristics and technical features of the equipment. The analysis results showed that the implementation of the CHP system is suitable for hotels and hospitals due to the characteristics of thermal load demand and heat-topower ratio. However, upon the consideration of the technical features of equipment, some buildings are suitable only to some specific distributed generation technologies. Ziher and Poredos (2006) has also carried out an economic analysis of the optimization of cooling production by using a profitability index evaluation method of the implementation of a CHP system based on a natural-gas turbine and absorption chiller in a hospital.

Energy efficiency utilization for small scale buildings such as convenience stores, minimarts, small restaurants. has not been the subject of much research due to the high investment costs and lack of skilled workers for implementation and maintenance. Also, the implementation of a CHP system for such buildings is rarely found. A number of studies, however, were conducted by considering the utilization of micro CHP system for some small scale buildings Hongbo et al. (2008) made a model for economical optimization of the CHP system in residential buildings in Japan including the optimal size of storage tanks. They found that the capacity of the CHP system is sensitive to capital costs, energy prices, carbon taxes and the electrical selling prices. Godefroy et al. (2007) proposed small CHPejector trigeneration for a research centre in the United Kingdom. In his study, total efficiency around 50\% was reached with simultaneous requirements for heat and cooling. Qunyin et al. (2012) proposed an alternative design and management of Combined Cooling, Heating and Power (CCHP) systems for residential buildings in Shanghai, which considered energy, economic and environmental assessments. The results showed that gas engines and fuel cells based on CCHP technology are realistic options from the energy and environmental standpoints, but are not economically feasible. Hongbo and Weijun (2010) analyzed the economic and environmental evaluation of the microCHP system for residential buildings in Japan. The results of the analysis recognized the fuel cell system as a better choice for residential buildings in Japan from both environmental and economic viewpoints. The results also showed optimal economic benefits, with yearly energy costs being reduced by about $26 \%$, as well as environmental benefits, with annual $\mathrm{CO}_{2}$ emissions were reduced by about $9 \%$. Michele et al. (2012) also proposed general guidelines for the design of micro-CHP systems for heating residential buildings. The results showed that CHP units with a thermal storage system can meet total thermal energy demands 
with a primary energy saving index of about $15-45 \%$. Also, from the economic viewpoint, the results showed the size of the CHP systems can be increased up to 5 $\mathrm{kWe}$ and $30-50 \mathrm{kWe}$, respectively, for single family houses and a block of flats.

As can be seen from the above review of previous studies, there is no research on the effects of a microCHP system for convenience stores in hot countries. Therefore, the purpose of this study is to investigate the influence by into a convenience store in Thailand. Firstly, the hourly energy demand has been investigated to see the characteristics of energy performance of convenience store in Thailand throughout the year 2011. Secondly, structures to gauge the energy flow of conventional system and $\mu$-CHP system were developed in order to analyze the reasonable sizing and efficiencies of $\mu$-CHP system for the store. Finally, an evaluation of primary energy savings and environmental benefits is undertaken by using assessment indices in the analysis methods.

\subsection{Case Study}

\subsubsection{Research Object}

This study examined a typical, real convenience store in Bangkok, Thailand, which is defined as a "stand alone" store. The store is in an isolated location without any other buildings or structures nearby the store. The layout of the store is shown in Fig. 1.

The store was built facing north. The building envelope of the store in the sales area is clear glass with a $10 \mathrm{~mm}$ thickness. On the West side, there is a noodle shop that is open from 8:00 am until 10:30 pm, which acts as an opaque wall to hinder sunlight to the West side of the store. In the non-sales area, the envelope's material is concrete wall on all sides.

\subsection{Energy Demand}

There are 3 major systems which consume significant energy in a typical convenience store-the Air Conditioning (A/C) system, the lighting system and the equipment of the store. The $\mathrm{A} / \mathrm{C}$ system in a convenience store in Thailand uses only a split-system in order to provide the cooling demand inside the sales area. From the author's survey's results, one convenience store normally used 3 or more A/C units with a capacity $44,000 \mathrm{BTU}(7.08 \mathrm{~kW})$ inside the sales area only. The lighting system in Thai convenience stores mostly use T8 fluorescent lamps (36 Watt and 18 Watt for the capacities) in order to provide lighting inside the store for both the sales and non-sales areas.
Even though the energy consumption of fluorescent tubes is not high, most convenience stores in Thailand always use an excessive number of fluorescent tubes inside the store and use them for $24 \mathrm{~h}$ even on sunny days. Equipment in convenience stores can be categorized into 2 types-that for refrigerating and that for heating purposes. Equipment for heating purposes will focus on the food preparation only, i.e., microwave, dim sum oven, roller grill machine, toaster, electric hot pot for instant noodles, coffee brewing equipment (some store).

Equipment for refrigeration purposes including freezers for frozen food, ice and ice cream, upright multi-shelf refrigerated display case (air-curtain), closed door reach-in refrigerator (for drinks), storage freezer, is responsible for a high amount of energy consumption.

Fig. 2 shows the relationship of the utilization of energy between each system for both the sales and nonsales areas. The analysis and investigation results from previous studies (Suapphong et al., 2012) found that the energy use in the sales area accounts for about $62 \%$ of total energy use in the store. The air-conditioning system used the highest amount of energy at about $46.2 \%$, followed by the equipment and lighting systems at $34.6 \%$ and $19.2 \%$, respectively.

In this study, on-site energy consumption in the store by equipment and the A/C system was measured throughout the year 2011 by installing a power meter on the panel board. Fig. 3 illustrates the measured monthly electrical energy demand during 2011. Two major energy demands are described in this study-equipment energy and A/C system energy demands. The equipment energy demand in this study includes the demand from the refrigerating system and heating systems. The lighting system of the store was composed of 138 36Watt fluorescent lamps and 8 18-Watt fluorescent lamps in the store sales and non-sales areas.

Figure 4 and 5 show the hourly and 1-day (average) load patterns of cooling and equipment (including lighting system) demands, respectively. It was found that peak load of equipment and cooling demands are $18.9 \mathrm{~kW}$ and $15.13 \mathrm{~kW}$, respectively. The cooling demand of the store is sensitive to climate conditions which can be seen from the shift in the energy demands during day time and which gradually decrease at night beginning at $6 \mathrm{pm}$. It can be seen that the tendency of equipment energy demand in one day is almost flat compared with cooling demand. However, the energy consumption of equipment is a little higher from $6 \mathrm{pm}$ due to the increase in customers after school and work. 


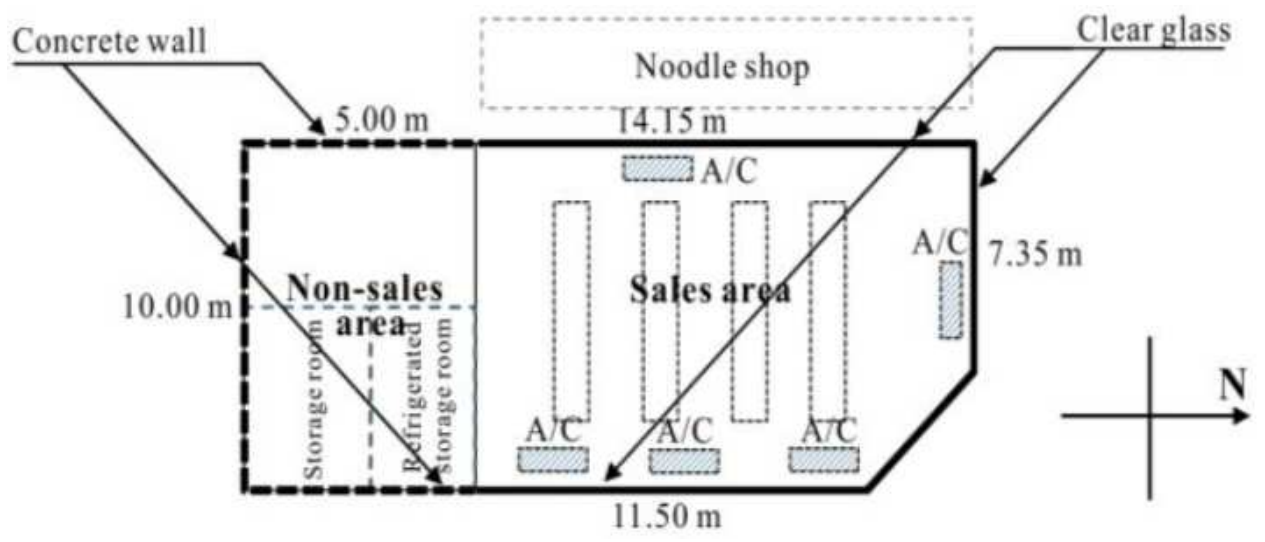

Fig. 1. Store's layout

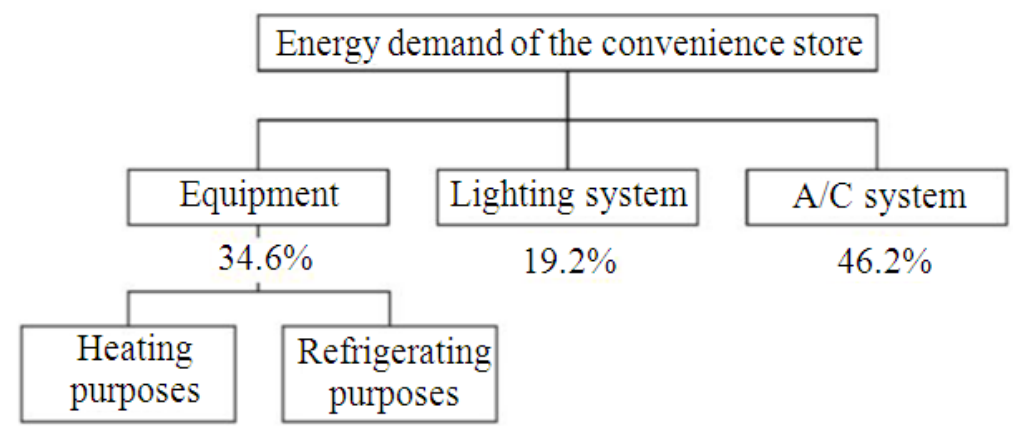

Fig. 2. Utilization systems affect total energy consumption of the convenience store

= Equipment energy demand $=\mathrm{A} / \mathrm{C}$ energy demand

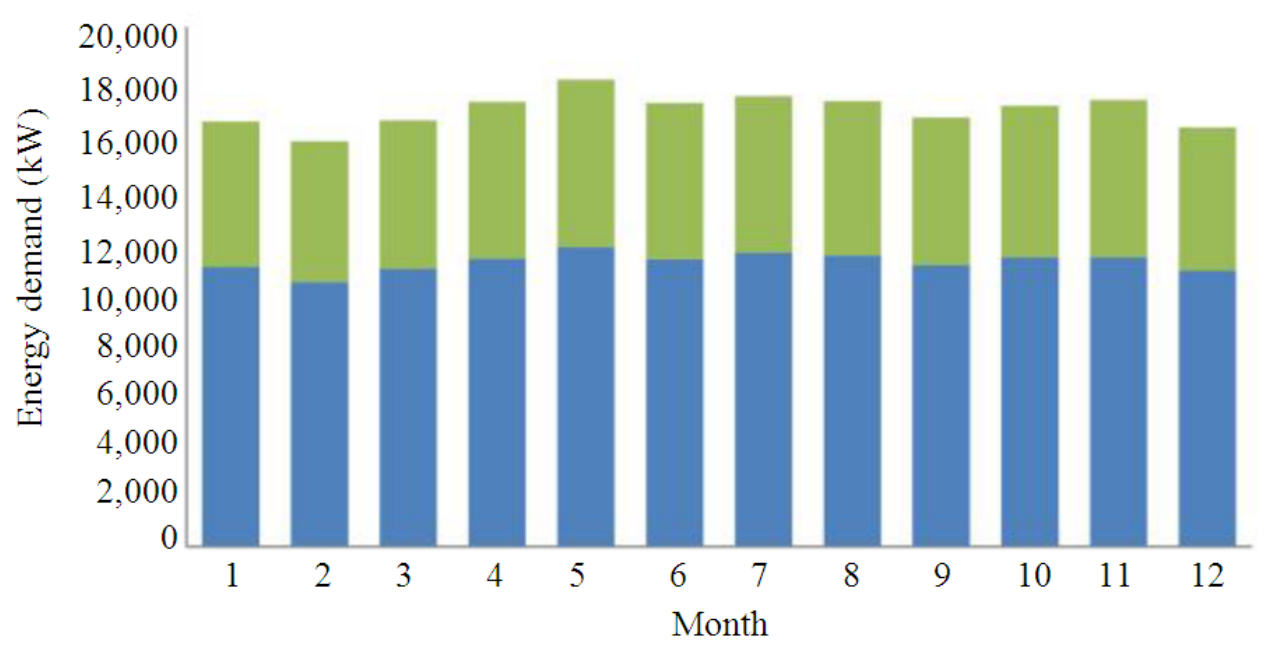

Fig. 3. Monthly electrical demand of $\mathrm{A} / \mathrm{C}$ and equipment 


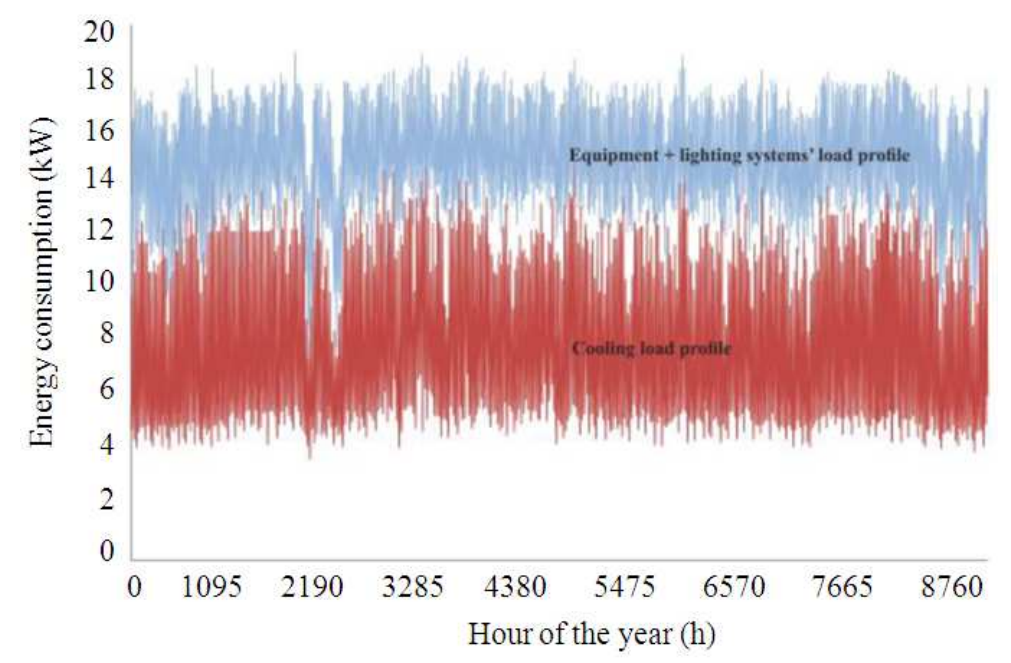

Fig. 4. One-year load profiles of cooling, equipment and lighting energy demands

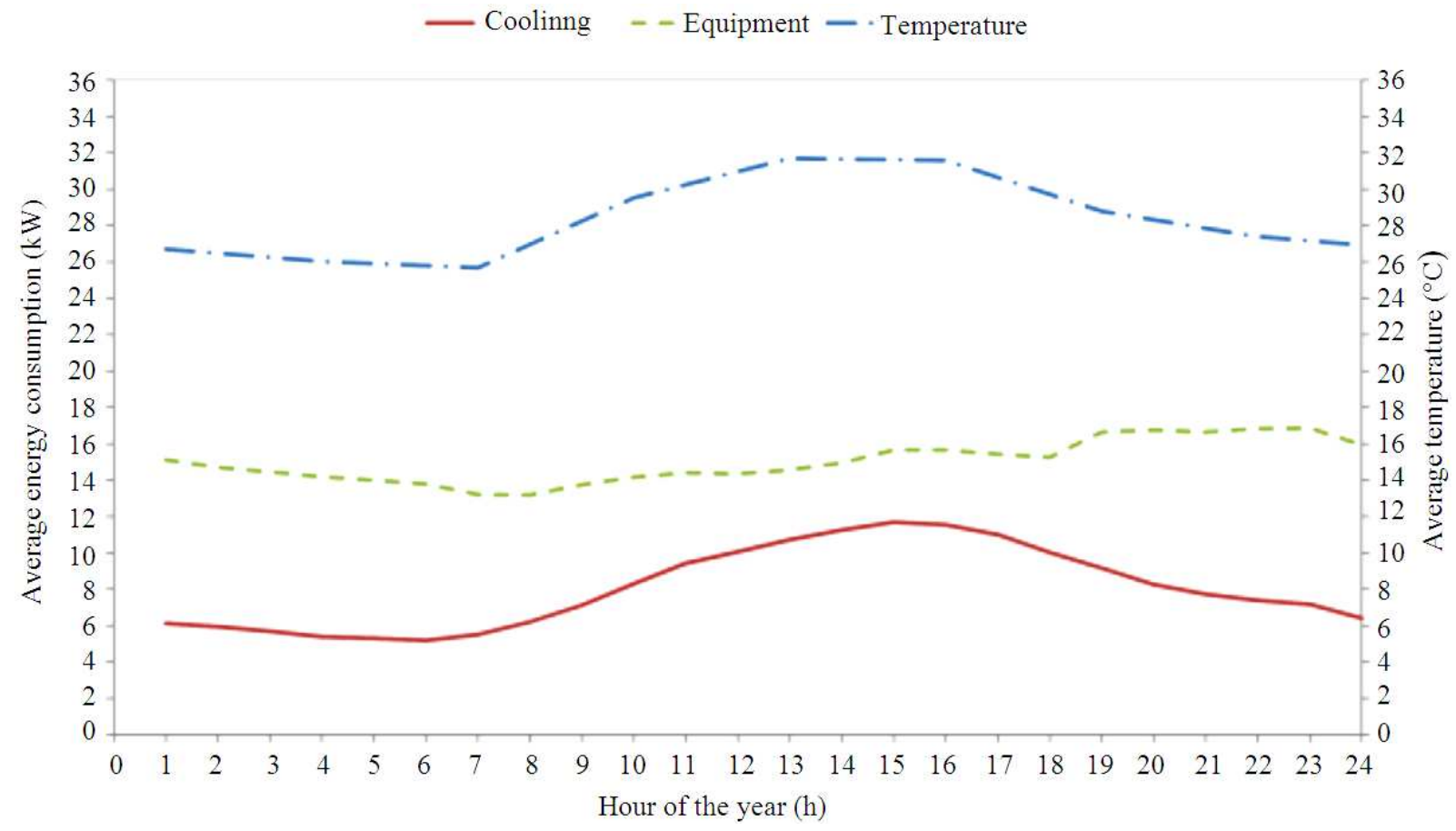

Fig. 5. Average value of 1-day load pattern for equipment and cooling demand and outdoor temperature

\section{MATERIALS AND METHODS}

\subsection{Modeling of $\mu$-CHP system}

The analysis of the $\mu$-CHP system comparing it to the conventional system was executed based on end-used demand data of hourly electricity energy consumption as illustrated in Fig. 6. Figure on the left is of the conventional system and the figure on the right is of the $\mu$-CHP system. The energy demand can be categorized into 2 major demands, namely, direct electrical energy consumption by equipment (lighting demand and equipment load) and cooling demand have been addressed in this study (Suapphong et al., 2014). 


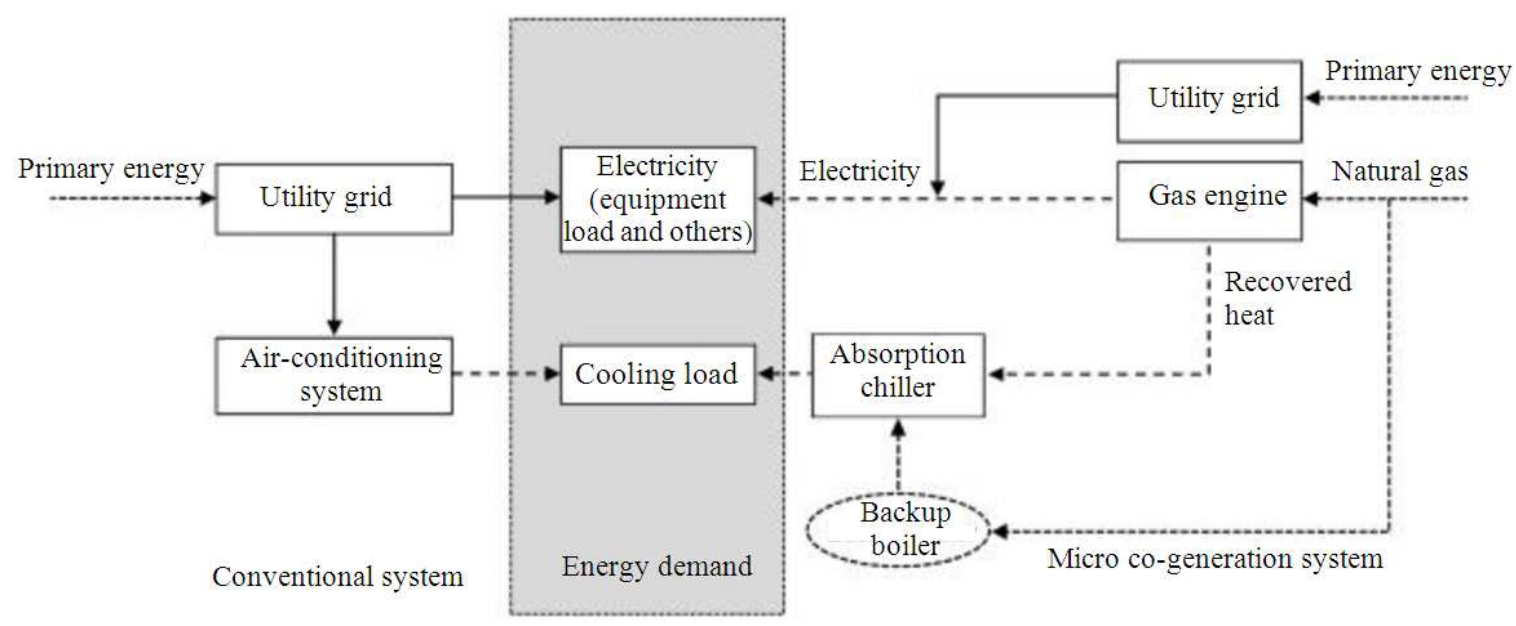

Fig. 6. Conventional and $\mu$-CHP energy supply systems (Suapphong et al., 2014)

For the conventional system, the utility grid serves all electrical demand which is used for not only direct power consumption, but also for space cooling load through the operation of the store's A/C system. For heating purposes, the store also uses electricity from the use of machines to provide hot water for noodles and frozen food. The $\mu$-CHP system in this study consists of a gas engine and absorption chiller. The mode of the gas engine is electricity tracking. The gas engine is used to meet the electrical and cooling loads with the use of an $\mathrm{A} / \mathrm{C}$ system through the absorption chiller. If the recovery of thermal energy from the gas engine does not fully satisfy the absorption chiller's needs, an additional boiler is used. However, if the recovered thermal energy goes over local needs, the surplus energy is released into the atmosphere.

\subsection{Assessment Index}

Two assessment indices (a primary energy saving index and an environmental assessment index) were considered in this paper in order to determine the optimal solution for the selection of the $\mu$-CHP capacity and efficiencies in Thailand's convenience store.

The consideration of energy characteristics and requirements which executed hourly throughout a oneyear (8760 period hrs) and technical information about electricity, as well as $\mu$-CHP performance characteristics were employed. In order to investigate the reasonable solutions for primary energy saving and maximum environmental benefits through the reduction of $\mathrm{CO}_{2}$ emission in this study, the operation of $\mu$-CHP system was assumed to track the electricity need.

\subsubsection{Primary Energy Saving Index}

In this paper, the energy performance index is expressed by the calculation of the Primary Energy Saving ratio (PES). The PES is defined as the ratio of the difference between primary energy input in the conventional energy system and the $\mu$-CHP system, to the primary energy input in the conventional system. It can be expressed in Equation 1:

$\mathrm{PES}=\left[\left(\mathrm{Q}_{\mathrm{CONV}}-\mathrm{Q}_{\mu \mathrm{CHP}}\right) / \mathrm{Q}_{\mathrm{CONV}}\right] .100 \%$

where, $\mathrm{Q}_{\mathrm{CONV}}$ and $\mathrm{Q}_{\mu \mathrm{CHP}}$ are the primary energy input in the conventional energy system and the $\mu$-CHP system, respectively. Total annual primary energy consumption by the conventional system is composed of the power consumption for electricity and cooling loads only, as illustrated in Equation 2. The total primary energy consumption of the $\mu$-CHP system is composed of the electrical energy consumption from the utility grid, the on-site power generation and the direct fuel combustion for the back-up boiler, as illustrated in Equation 3:

$$
\begin{aligned}
& \mathrm{Q}_{\text {CONV }}=\frac{\mathrm{Q}_{\text {POWER }}^{\text {LOAD }}}{\eta_{\text {GRID }}}+\frac{Q_{\text {COOLING }}^{\text {LOAD }}}{\operatorname{COP}_{\text {COOLING }}^{\text {AC }} \eta_{\text {GRID }}} \\
& Q_{\mu C H P}=\frac{Q_{\text {POWER }}^{\text {GRID }}}{\eta_{\text {GRID }}}+\frac{Q_{\text {POWER }}^{\text {MCHP }}}{\eta_{\text {E }}}+\frac{Q_{\text {COOLLING }}^{\text {BOLLR }}}{\eta_{\text {BOIOLER }}}
\end{aligned}
$$

where, $\mathrm{Q}_{\text {POWER }}^{\text {LAd }}$ and $\mathrm{Q}_{\text {COOLNG }}^{\text {LAd }}$ are the electricity load for equipment and the space cooling of the store,

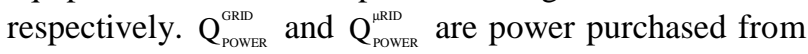
the utility grid and power generation of the $\mu$-CHP 
system, respectively. $\mathrm{Q}_{\text {соо口ия }}^{\text {вонr }}$ is the purchased power from the natural gas supply for the back-up boiler in order to satisfy the heat demand for the absorption chiller. $\eta_{\text {GRID }}, \eta_{\mathrm{E}}$ and $\eta_{\text {BOILER }}$ denote the efficiency of the utility grid, electricity efficiency of the $\mu$-CHP system and the efficiency of back-up boiler, respectively. $\mathrm{C}_{\text {Coolng }}^{\wedge \mathrm{NC}}$ indicates the coefficient of performance of the $\mathrm{A} / \mathrm{C}$ system utilized in the conventional system.

\subsubsection{Envrionmental Assessment Index}

In this study, the $\mathrm{CO}_{2}$ Emission Reduction Ratio (CER) is used to evaluate the environmental effect of the $\mu$-CHP system and is defined as the ratio of the difference between $\mathrm{CO}_{2}$ emissions from the conventional system and the $\mu$-CHP system, to the $\mathrm{CO}_{2}$ emissions from the conventional system as follows Equation 4:

$$
\mathrm{CER}=\left[\left(\mathrm{E}_{\mathrm{CONV}}^{\mathrm{CO}_{2}}-\mathrm{E}_{\mu \mathrm{CHP}}^{\mathrm{CO}_{2}}\right) / \mathrm{E}_{\mathrm{CONV}}^{\mathrm{CO}_{2}}\right] \cdot 100 \%
$$

where, $\mathrm{E}_{\mathrm{CoN}}^{\mathrm{CO}_{2}}$ and $\mathrm{E}_{\mathrm{\mu CCP}}^{\mathrm{CO}_{2}}$ are the annual $\mathrm{CO}_{2}$ emissions of the conventional system and the $\mu$-CHP system, respectively. Calculations of the annual $\mathrm{CO}_{2}$ emissions for both systems are based on the results from the primary energy input multiplied by the Carbon Contents of grid Electricity $\left(\mathrm{CC}_{\mathrm{ELEC}}\right)$ and natural $\mathrm{Gas}\left(\mathrm{CC}_{\mathrm{GAS}}\right)$, which are illustrated in the Equation 5 and 6:

$$
\begin{aligned}
& \mathrm{E}_{\mathrm{CONV}}^{\mathrm{CO}_{2}}=\left(\frac{\mathrm{Q}_{\mathrm{POWER}}^{\mathrm{LOAD}}}{\eta_{\mathrm{GRID}}}+\frac{\mathrm{Q}_{\mathrm{COOLING}}^{\mathrm{LOAD}}}{\mathrm{COP}_{\mathrm{COOLING}}^{\mathrm{A} / \mathrm{C}} \cdot \eta_{\mathrm{GRID}}}\right) \cdot \mathrm{CC}_{\mathrm{ELEC}} \\
& \mathrm{E}_{\mu \mathrm{CHP}}^{\mathrm{CO}_{2}}=\frac{\mathrm{Q}_{\mathrm{POWER}}^{\mathrm{GRID}}}{\eta_{\mathrm{GRID}}} \cdot \mathrm{CC}_{\mathrm{ELEC}}+\left(\frac{\mathrm{Q}_{\mathrm{POWER}}^{\mu \mathrm{CHP}}}{\eta_{\mathrm{E}}}+\frac{\mathrm{Q}_{\text {COOLING }}^{\text {BOILR }}}{\eta_{\text {BOILER }}}\right) \cdot \mathrm{CC}_{\mathrm{GAS}}
\end{aligned}
$$

\subsection{Data Assumptions for Analysis}

In this study, a $\mu$-CHP system driven by natural gas is considered, combined with the utility electricity and $\mathrm{A} / \mathrm{C}$ system in order to accommodate the energy demands. The sensitivity analysis has been considered in order to verify the acceptable gas engine's performances by varying the value of machine's electrical and thermal efficiencies $\left(\eta_{\mathrm{E}}\right.$ and $\left.\eta_{\mathrm{H}}\right)$ from $25 \%$ to $45 \%$. The capacity of the $\mu$-CHP system varies from $3 \mathrm{~kW}$ to $30 \mathrm{~kW}$ in order to correspond to load characteristics of the store. The Coefficient of Performance (COP) of A/C system from measurement is around 3 . The efficiencies of the electricity utility grid and back-up boiler are assumed to be 30 and $85 \%$, respectively. Table 1 summarizes the technical data for this analysis.

Table 1. Data assumptions for the analysis

\begin{tabular}{lll}
\hline Item & Parameter & Value \\
\hline \multirow{2}{*}{ Electricity utility grid } & Efficiency $(\%)$ & 30 \\
Natural gas & Carbon intensity (g-C/kWh) & 262.16 \\
A/C system & Carbon intensity (g-C/kWh) & 15.29 \\
Absorption chiller & COP & 3 \\
Back-up boiler & Efficiency $(\%)$ & 1.1 \\
& Capacity (kW) & 8.5 \\
& & $3,6,9,12,15,18$, \\
$\mu$-CHP Plant & $\eta_{\mathrm{E}}(\%)$ & $21,24,27,30$ \\
& $\eta_{\mathrm{H}}(\%)$ & $25,30,35,40,45$ \\
& & $25,30,35,40,45$ \\
\hline
\end{tabular}

\section{RESULTS}

\subsection{Energy Performance Assessment}

In this section, PES values for various options with different $\mu$-CHP's capacity are calculated. The electrical efficiency $\left(\eta_{E}\right)$ and thermal efficiency $\left(\eta_{H}\right)$ of $\mu$-CHP system is assumed to be $35 \%$ and $45 \%$, respectively, in order to analyze the reasonable capacity for maximizing the PES. From Fig. 7, below $15 \mathrm{~kW}$, the increase of $\mu$-CHP's capacity results in a significant energy saving. Above $15 \mathrm{~kW}$ for the $\mu$ CHP's capacity, the change of PES becomes slower. Finally, the PES becomes stable from the utilization of $\mu$-CHP's capacity above $18 \mathrm{~kW}$. It is found that, the PES value can be increased up to $45 \%$ from the variation of the gas engine's efficiencies.

Fig. 8 represents the PES values of the $\mu$-CHP system under the capacity of $15 \mathrm{~kW}$ with the $\eta_{\mathrm{E}}$ and $\eta_{\mathrm{H}}$ varied from $25 \%$ to $45 \%$. It is found that, increasing of $\eta_{E}$ of the $\mu$-CHP at the low range of the efficiency will have a significant effect on the PES value, e.g., increasing of $\eta_{E}$ from $25 \%$ to $30 \%$, PES value can be increased by 8.9 $10.6 \%$. On the other hand, at high value of $\eta_{\mathrm{E}}$, the increase of the efficiency results in a slight increase of PES value, e.g., increasing the $\eta_{\mathrm{E}}$ from $40 \%$ to $45 \%$, only gives PES value an increase of $2.7-3.6 \%$.

It is also found that the $\eta_{\mathrm{H}}$ of the $\mu$-CHP affects the change of the PES value but is not as significant as the change in $\eta_{E}$. Increasing the $\eta_{H}$ at a low rate results in a high change of PES value, e.g., with the increase of the $\eta_{\mathrm{H}}$ from $25 \%$ to $30 \%$, PES value will increase by 2.8 $4.1 \%$. On the contrary, the increase of the $\eta_{H}$ at a high rate results in a slight change of PES value, e.g., with the increase of the $\eta_{H}$ from $40 \%$ to $45 \%$, PES value will be raised by $1.5-2.7 \%$. 


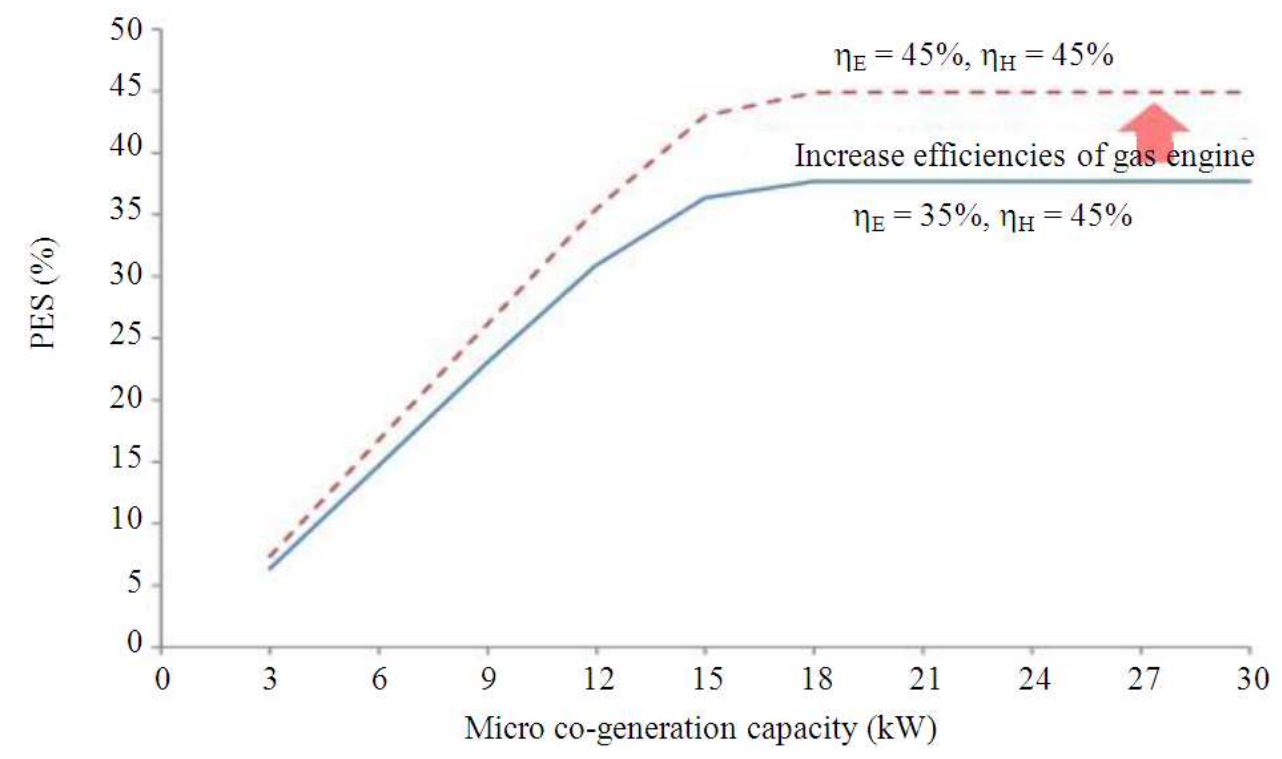

Fig. 7. PES value with various $\mu$-CHP capacities

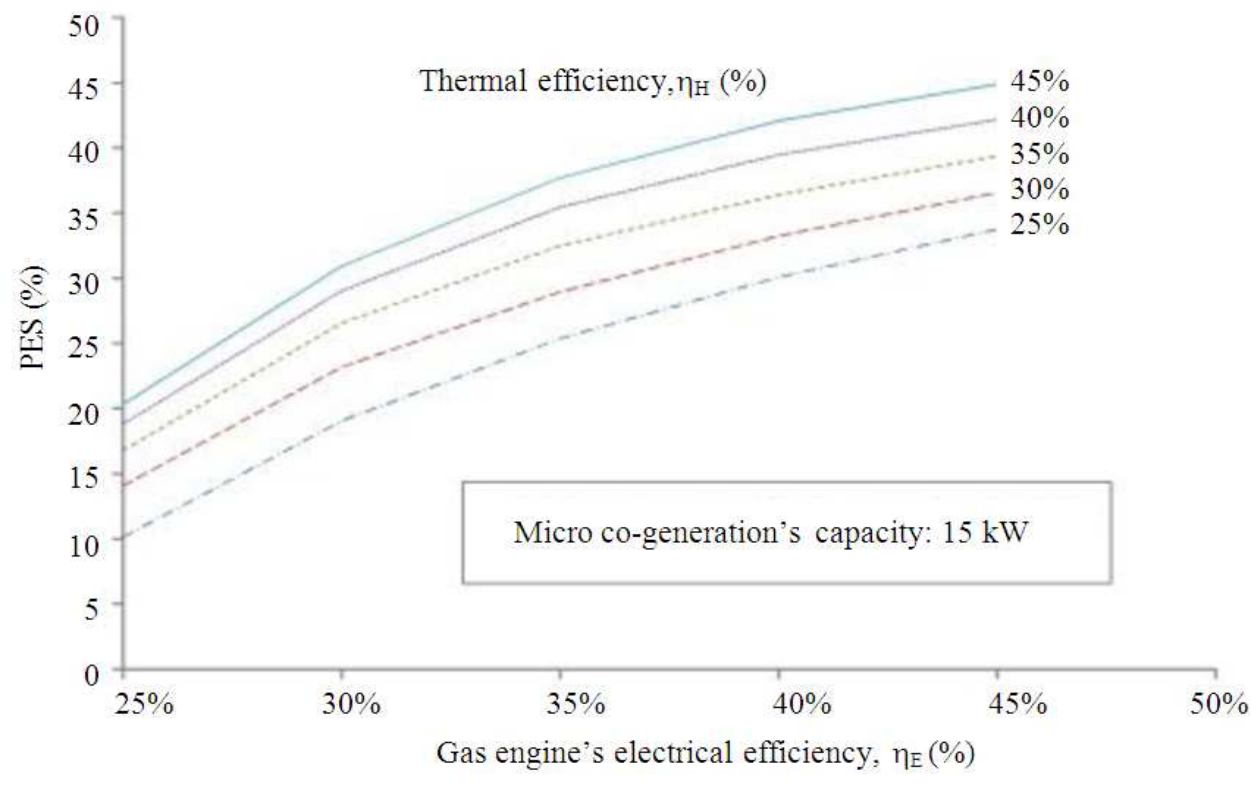

Fig. 8. PES value with various gas engines' efficiencies

\subsection{Environmental Performance Assessment}

Fig. 9 shows the $\mathrm{CO}_{2}$ Emission Reduction Ratio (CER) values for various capacities of $\mu$-CHP systems with $\eta_{\mathrm{E}}$ and $\eta_{\mathrm{H}}$ assumed at 35 and $45 \%$, respectively. Similar to the phenomena of energy performance, increasing the $\mu$-CHP's capacity results in a significant reduction of $\mathrm{CO}_{2}$ emission below $15 \mathrm{~kW}$.
Above $15 \mathrm{~kW}$ for the $\mu$-CHP's capacity, the change in CER value becomes slower. Finally, the CER value becomes stable from the $\mu$-CHP's capacity above 18 $\mathrm{kW}$. It was found that the $\mathrm{CO}_{2}$ emission reduction ratio can be increased up to $88.4 \%$ from the variation of the gas engine's efficiencies.

Fig. 10 illustrates the $\mathrm{CO}_{2}$ emission Reduction Ratio (CER) from the $\mu$-CHP system with the capacity $15 \mathrm{~kW}$ 
integrated with the $\eta_{\mathrm{E}}$ and $\eta_{\mathrm{H}}$ from 25 to $45 \%$. Increase of $\eta_{\mathrm{E}}$ of $\mu$-CHP at a low value results in a significant increase of CER value, e.g., with the increase of $\eta_{\mathrm{E}}$ from 25 to $30 \%$, CER value can be increased by $1.9-2.2 \%$. In contrast, at a high value, the change of the $\eta_{E}$ results in a slight increase of CER value, e.g., with the increase of $\eta_{E}$ from $40 \%$ to $45 \%$, but CER value can be increased only by $0.6-0.8 \%$.
The thermal efficiency $\left(\eta_{H}\right)$ of gas engines has less effect on the CER value for all rates of efficiency. Increasing the $\eta_{\mathrm{H}}$ at lower rates results in a slight change of CER value, e.g., with the increase of the $\eta_{\mathrm{H}}$ from 25 to $30 \%$, the CER value is raised by $0.6-0.8 \%$. Furthermore, increasing the $\eta_{\mathrm{H}}$ at higher rates also results in a slight change of CER value, e.g., with the increase of the $\eta_{H}$ from 40 to $45 \%$, CER value is raised by $0.3-0.6 \%$.

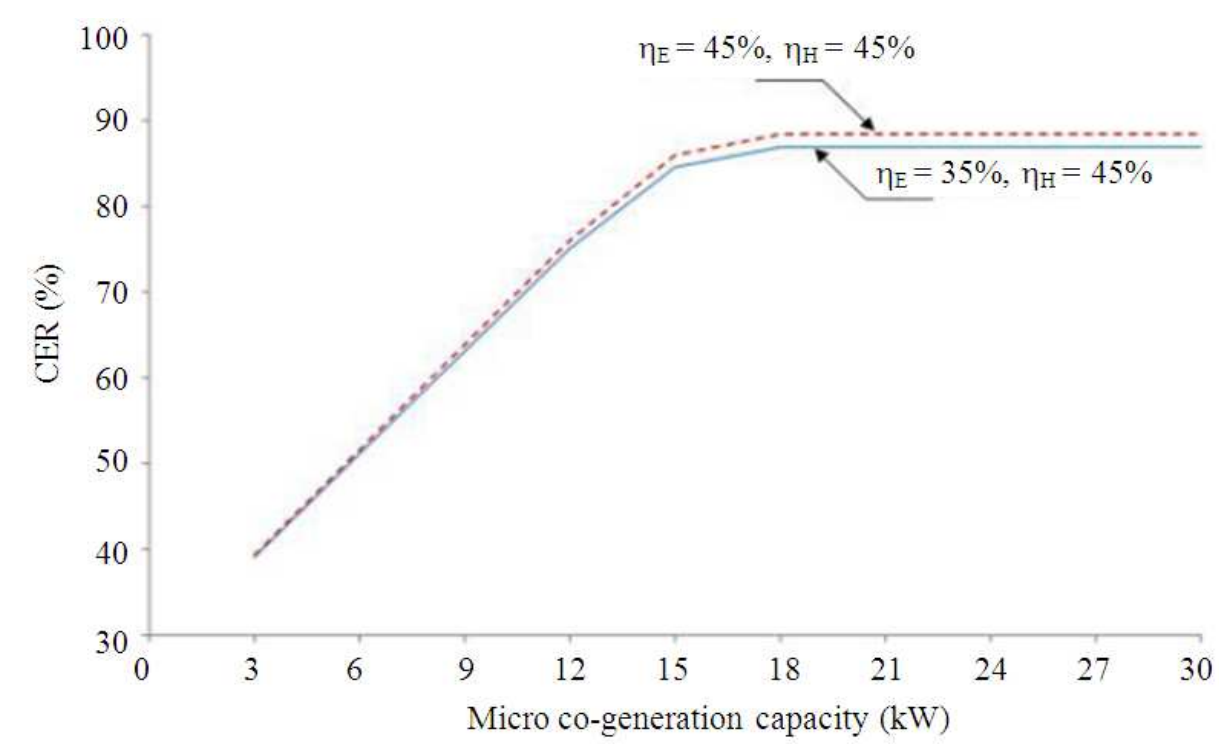

Fig. 9. CER value with various $\mu$-CHP capacities

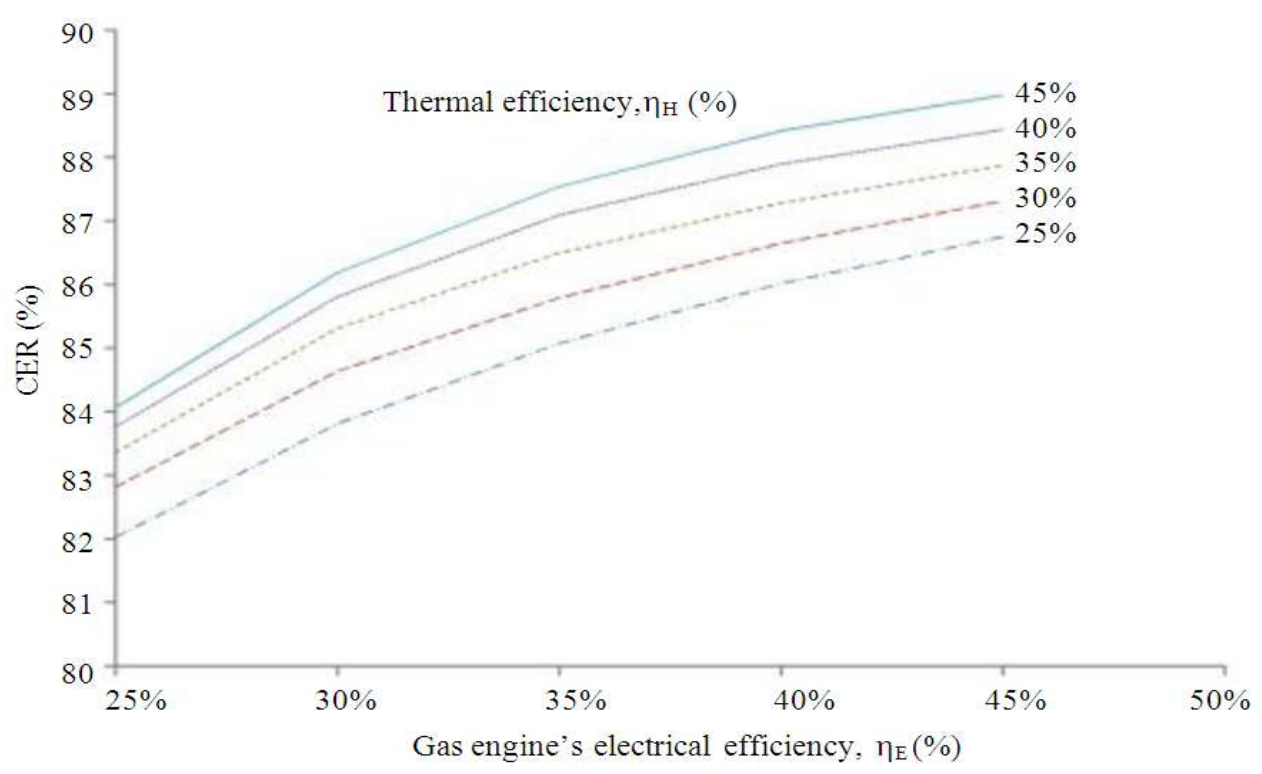

Fig. 10. CER value with various gas engines' efficiencies 


\section{DISCUSSION}

The results shown in Fig. 7 and 9 can be explained from the consideration of load patterns of the convenience store and $\mu$-CHP system for both equipment and the cooling load as illustrated in Fig. 11 and 12. Figure 11 illustrates the load patterns of the equipment demand of the convenience store and electricity produced by the $\mu$-CHP system. Zone 1 in this Figure denotes the amount of electricity that is still needed from the utility grid. It was found that increasing the $\mu$-CHP's capacity will result in the reduction in zone 1 , which means much more electricity for the equipment needs of the store can be supplied by a $\mu$-CHP system. When the capacity is higher than $18 \mathrm{~kW}$, full electricity for equipment can be produced by a $\mu$-CHP system, which means the store is totally independent of the grid electricity supply (Suapphong et al., 2014).

Figure 12 illustrates the load duration curve of the cooling demand and supply from the $\mu$-CHP system with a $15 \mathrm{~kW}$ capacity, with 35 and $45 \%$ for $\eta_{\mathrm{E}}$ and $\eta_{\mathrm{H}}$, respectively. Load duration curves of the cooling demand and production from the $\mu$-CHP system of the store are divided into 3 zones, namely zone 1, 2 and 3 which represented the amount of heat use in different states. Zone 1 represents the amount of recovery heat which is produced by the $\mu$-CHP system. Zone 2 represents the amount of heat from the back-up boiler which provides additional heat to produce the cooling energy. Zone 3 is the amount of surplus energy which is produced from the $\mu$-CHP that exceeds the requirements and which is released into the atmosphere. It can be seen that increasing of the $\mu$-CHP capacity will enlarge the area of zone 1 and reduce the size of zone 2 , which means a large part of the cooling demand can be met by recovery heat from the $\mu$-CHP system. However, with the increase of the $\mu$-CHP capacity, the area of Zone 3 will also be increased, which means a lot of waste heat will be released into the environment. From the viewpoint of making good use of recovery heat, the optimum capacity of the $\mu$-CHP system will be around 9 $\mathrm{kW}$, at which the area of Zone 3 will be near zero and recovery heat from the $\mu$-CHP system is totally used.

The analysis of results shows that considering the efficient energy saving, the $\mu$-CHP sizing of $15 \mathrm{~kW}$ is the optimal solution for this convenience store. Above the 18 $\mathrm{kW}$ capacity, the electricity supply can be defined as a "grid independence" pattern, which means during operation, no electricity is supplied from the utility grid even though a high amount of surplus heat cannot be used. On the other hand, the consideration of the minimization of waste heat can lead to a decision to select a $9 \mathrm{~kW} \mu$ CHP system. But in this case, the additional electricity supply for the equipment load from the grid and heat supply from the back-up boiler is needed in order to satisfy the energy need (Suapphong et al., 2014).

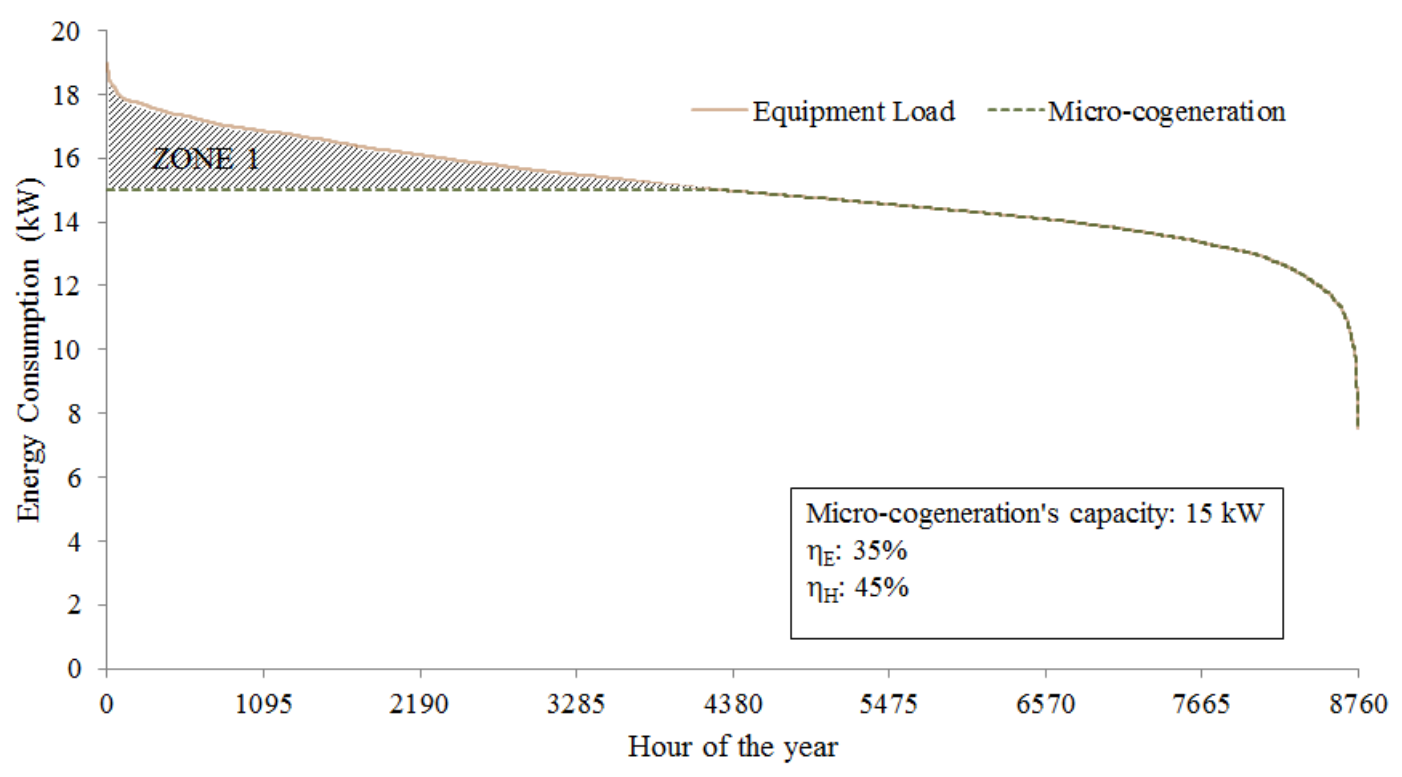

Fig. 11. Load duration curves of the equipment demand and load production from the $\mu$-CHP system (Suapphong et al., 2014) 


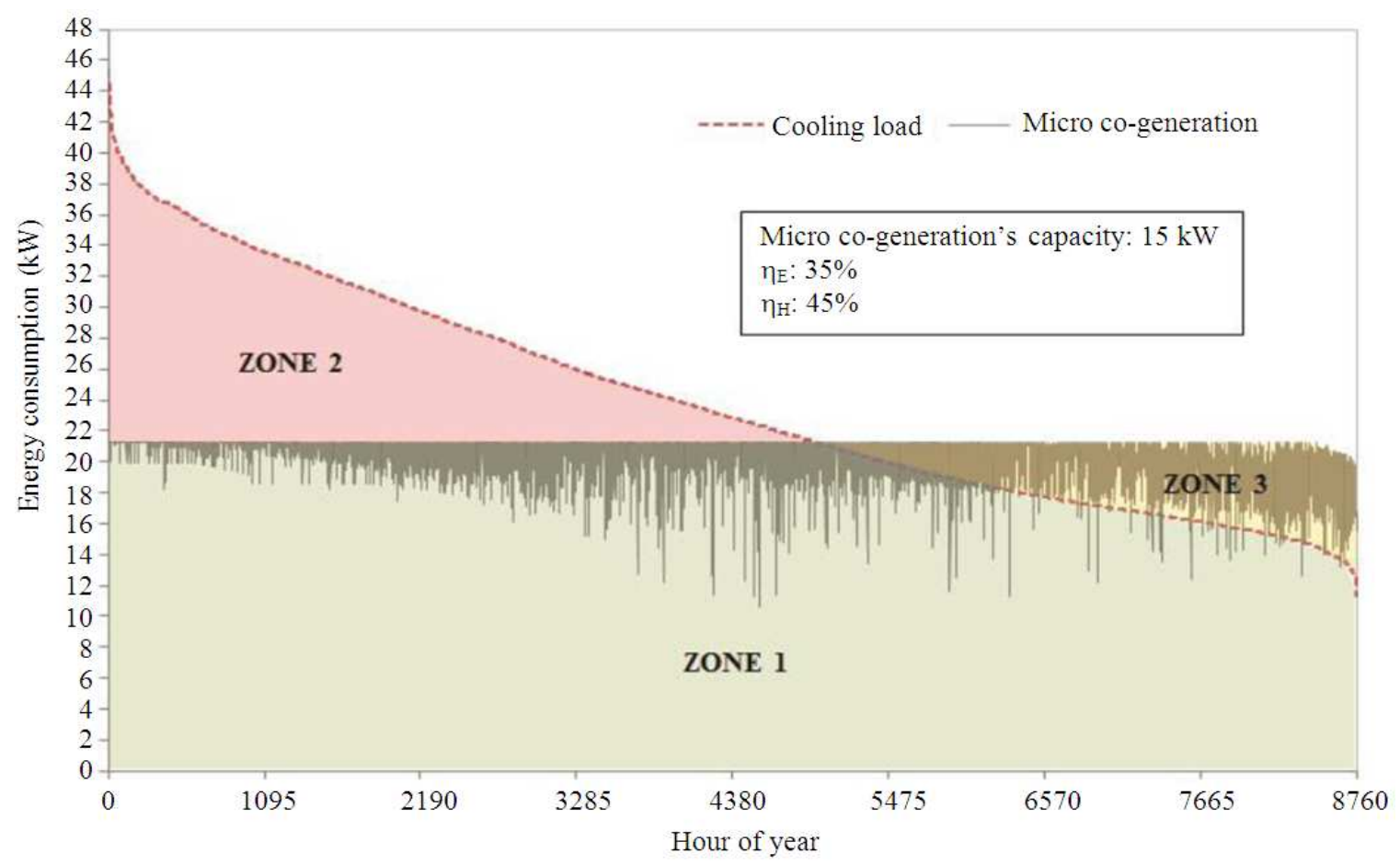

Fig. 12. Load duration curves of the cooling demand and the load production from $\mu$-CHP system (Suapphong et al., 2014)

\section{CONCLUSION}

This study tries to clarify the impact of the $\mu$-CHP system in the convenience stores in Thailand regarding energy saving and environmental improvement through on-site investigation and sensitivity analysis. The following results were found upon analysis of the data.

In order to maximize the primary energy saving and $\mathrm{CO}_{2}$ emission reduction, the $15 \mathrm{~kW} \mu$-CHP system is the optimal solution in this case. By considering the "independence" from the grid supply, the proper capacity should be $18 \mathrm{~kW}$ or more, which means no need of the electricity supply from utility grid during the operation period. On the other hand, in order to minimize the waste heat, or in other word to make good use of recovered heat from the $\mu$-CHP system, a $9 \mathrm{~kW} \mu$-CHP system will give the most efficient results in energy saving and $\mathrm{CO}_{2}$ emission reduction although in this case, additional electrical energy supply for equipment needs and heat supply from the back-up boiler will be needed.

Electrical and thermal efficiencies $\left(\eta_{\mathrm{E}}\right.$ and $\left.\eta_{\mathrm{H}}\right)$ of gas engines are also important factors to enhance the performance of the $\mu$-CHP system. In the case of energy saving, higher values for both efficiencies will increase Primary Energy Saving ratio (PES) up to $45 \%$. In addition, the $\mathrm{CO}_{2}$ Emission Reduction Ratio (CER) will be increased up to $88 \%$ at the higher value of both efficiencies. The results show that $\eta_{E}$ influences energy saving and $\mathrm{CO}_{2}$ emission reduction more than $\eta_{\mathrm{H}}$ for all $\mu$-CHP capacities.

The introduction of the $\mu$-CHP system to Thailand's convenience stores shows good results regarding both energy conservation and $\mathrm{CO}_{2}$ emission reduction. However, the selection of the reasonable capacity of the $\mu$-CHP system depends on the characteristic of the load profile and the objective of the utilization.

\section{REFERENCES}

Godefroy, J., R. Boukhanouf and S. Riffat, 2007. Design, testing and mathematical modelling of a small-scale CHP and cooling system (small CHP-ejector trigeneration). Applied Thermal Eng., 27: 68-77. DOI: 10.1016/j.applthermaleng.2006.04.029

Hongbo, R. and G. Weijun, 2010. Economic and environmental evaluation of micro CHP systems with different operating modes for residential buildings in Japan. Energy Build., 42: 853-861. DOI: 10.1016/j.enbuild.2009.12.007 
Hongbo, R., G. Weijun and R. Yingjun, 2008. Optimal sizing for residential CHP system. Applied Thermal Eng., 28: 514-523. DOI: 10.1016/j.applthermaleng.2007.05.001

Iman, B., G. Barat and A. Mohammad, 2008. Economical Investigation of ICECHP using gasohol-a case study for Iran. Am. J. Applied Sci., 5: 1206-1211. DOI: 10.3844/ajassp.2008.1206.1211

Maidment, G., X. Zhao, S. Riffat and G. Prosser, 1999. Application of combined heat-and-power and absorption cooling in a supermarket. Applied Energy, 63: 169-190. DOI: 10.1016/S0306-2619(99)00026-4

Michele, B., P. Andrea and S. Pier, 2012. Guidelines for residential micro-CHP systems design. Applied Energy, $\quad 97$ : 673-685. 10.1016/j.apenergy.2011.11.023

Pedro, M. and S. Amanda, 2012. Evaluation of the potential emissions reductions from the use of CHP systems in different commercial buildings. Build. Environ., 53: 74-82. DOI: 10.1016/j.buildenv.2012.01.006

Qunyin, G., R. Hongbo, G. Weijun and R. Jianxing, 2012. Integrated assessment of combined cooling heating and power systems under different design and management options for residential buildings in Shanghai. Energy Build., 51: 143-152. DOI: 10.1016/j.enbuild.2012.04.023

Sommart, K. and C. Chullapong, 2005. Potential for cogeneration and absorption chiller in a supercenter building. Proceedings of the 1st Conference on Energy Network of Thailand, May 11-13, Chonburi, Thailand, pp: 244-249.
Suapphong, K., I. Pawinee, G. Weijun and K. Soichiro, 2012. Preliminary analysis of effect of envelope improvement to cooling load efficiency of Thailand's convenience store. Proceedings of the Society of Heating, Air-conditioning and Sanitary Engineers of Japan Conference, Jun. 2-2, Kagoshima, Japan, pp: 105-110.

Suapphong, K., G. Weijun and I. Pawinee, 2014. Feasibility study of optimal sizing of microcogeneration system for convenience stores in Bangkok. Energy Power Eng., 6: 69-81. DOI: 10.4236/epe.2014.65008

Sugiartha, N., S. Tassou, I. Chaer and D. Marriott, 2009. Trigeneration in food retail: An energetic, economic and environmental evaluation for a supermarket application. Applied Thermal Eng., 29: 2624-2632. DOI: 10.1016/j.applthermaleng.2008.11.018

Yingjun, R., L. Qingrong, Z. Weiguo, F. Ryan and G. Weijun et al., 2009. Optimal option of distributed generation technologies for various commercial buildings. Applied Energy, 86: 1641-1653. DOI: 10.1016/j.apenergy.2009.01.016

Ziher, D. and A. Poredos, 2006. Economics of a trigeneration system in a hospital. Applied Thermal Eng., 26: 680-687. DOI: 10.1016/j.applthermaleng.2005.09.007 